\title{
De perceptos a frames: cognição ecológica e linguagem
}

\author{
Paulo Henrique Duque*
}

\begin{abstract}
Resumo
Neste artigo, proponho uma abordagem ecológica de cognição e linguagem, demonstrando que os processos de conceptualização parecem emergir da interação organismo-ambiente. Tal abordagem cognitiva exige a coordenação dos dois extremos dessa emergência e a consideração de que o uso da linguagem inevitavelmente envolve tanto os processos iniciais de interação do organismo com o ambiente quanto as estruturas e os processos que emergem dessas interações. De acordo com a abordagem aqui proposta, desenvolvemos conceitos e reorientamos nossos pensamentos sobre o mundo por meio de um mecanismo conhecido como framing, isto é, o recurso discursivo-cognitivo de que dispomos para (re)modelar circuitos neurais (ou frames).

Palavras-Chave: Cognição Ecológica. Semântica Cognitiva. Framing.
\end{abstract}

* Universidade Federal do Rio Grande do Norte (UFRN). Professor Associado do Departamento de Letras e do Programa de Pós-graduação em Estudos da Linguagem. 


\section{Introdução}

O presente artigo se enquadra nos estudos sobre a interface entre linguística e cognição, de acordo com os quais a cognição integra cérebro, corpo e ambiente. De acordo com tal perspectiva, o sistema cognitivo emerge da atuação do corpo no ambiente, ou seja, com as informações perceptuais obtidas durante a exploração do ambiente, o cérebro coordena a montagem de circuitos percepto-motores de execução de tarefas de complexidade crescente. Um dos pontos críticos do desenvolvimento do sistema cognitivo é a formação de conceitos. Não há consenso sobre como ocorre esse desenvolvimento, mas sua elucidação nos parece crucial para a compreensão do que de fato é cognição.

Sendo assim, proponho aqui uma abordagem ecológica de cognição e linguagem, demonstrando que os processos de conceptualização parecem emergir da interação organismo-ambiente. Tal abordagem cognitiva exige a coordenação dos dois extremos dessa emergência e a consideração de que o uso da linguagem inevitavelmente envolve tanto os processos iniciais de interação do organismo com o ambiente quanto as estruturas e os processos que emergem dessas interações.

Há duas perspectivas predominantes para os estudos da cognição de base corporificada: a abordagem moderada e a abordagem radical. A primeira se sustenta no pressuposto de que a cognição sofre algumas influências da corporalidade (EERLAND et al., 2011) ou do ambiente (ADAM; GALINSKY, 2012). A segunda, ao contrário, se sustenta no pressuposto de que a cognição está fortemente enraizada na corporalidade (LAKOFF; JOHNSON, 1980, 1999; MILES et al., 2010). É possível colocarmos esses dois pontos de vista nos extremos de um contínuo que pode apresentar até seis (WILSON, 2002) noções de corporalidade distintas.

A noção de corporalidade que evoco aqui é a defendida por Shapiro (2011): a integração homem-ambiente constitui-se como condição inicial para o desenvolvimento do sistema cognitivo. Nessa abordagem, nossos corpos, orientados pela percepção, executam tarefas específicas, guiadas por intenções, tais como alcançar objetos, chegar a locais específicos, escalar locais íngremes etc. Nesse sentido, a interação direta entre organismo e ambiente fundamenta e perpassa todo e qualquer processo cognitivo. Interação, aqui, corresponde a um tipo de ação que ocorre quando dois ou mais "objetos" provocam efeitos uns sobre os outros. Nesse sentido, o organismo age no ambiente e o ambiente age 
no organismo produzindo alterações e rearranjos mútuos. Para esse enquadre ecológico de cognição, a noção de efeitos mútuos substitui a noção unidirecional de que apenas o ambiente é alterado pelas nossas ações.

Quanto ao papel do cérebro dentro da abordagem ecológica de cognição, tratase de um recurso de resposta rápida que coordena a montagem de dispositivos de tarefas específicas. Circuitos neurais (ou frames) são modelados e remodelados para dar conta da cognição distribuída (por todo o corpo) e estendida (para além do corpo). Esses circuitos são (re) modelados pelo reforço constante de redes neurais que disparam juntas na execução recorrente da mesma tarefa específica. Dentro dessa perspectiva de cognição, o cérebro participa da cognição para garantir certa estabilidade e rapidez aos processos que dependem de informações perceptuais e motoras não presentes no entorno ambiental. Nesse sentido, o termo cognição, adotado aqui, corresponde à integração de estruturas conceptuais (frames) com a estrutura física do ambiente e as especificidades do corpo humano.

\section{Percepção, informação e affordance}

Do ponto de vista do realismo indireto, que pressupõe a mediação entre o mundo real e o organismo que o percebe, temos o realismo racionalista e o realismo experiencialista. No primeiro, o mundo físico é percebido a partir da razão, ou seja, o objeto ou o evento é percebido a partir do momento em que o observador associa uma representação interna pré-existente a esse objeto. Nessa concepção, apesar de o mundo ser considerado real, ele é abstrato, pois o observador, por meio de uma mediação, faz associações entre o que é inato e o que é disponibilizado para ser percebido. No segundo, a percepção do mundo físico real ocorre a partir da experiência, isto é, do contato do ser que percebe com aquilo que é percebido. A experiência primária é o mecanismo desencadeador da representação interna do mundo real, que induz a percepção.

Apesar da diferença evidente entre o racionalismo e o experiencialismo, estes apresentam um ponto de convergência: pressupõem a existência de representação interna para que o mundo possa ser percebido. Há representação interna, não importa se o processo de percepção seja desencadeado pela razão ou resultante de processos internos construídos a partir da experiência. Se a existência de objetos e eventos independe de esses objetos e eventos serem percebidos, por que a percepção precisa ser um processo mediado? Por que separarmos a coisa 
percebida do seu observador? Admitir as premissas do realismo indireto é como assumir um realismo parcial. Parece contraditório que, embora o mundo exista independentemente da percepção, a percepção ocorra de forma indireta. Devido a essa contradição, Shaw, Turvey e Mace (1982) defendem que a percepção ocorre de forma direta, sem mediação, sem nenhum processo interno ou mental, sem necessidade de qualquer suplementação, representação, abstração, associação, processamento, inferência ou memória.

Para admitirmos que objetos e eventos existem independentemente do observador, precisamos rever os três princípios básicos do realismo indireto: a) que são estímulos físicos, fragmentados e aleatórios, que desencadeiam a percepção do mundo; b) que é necessário algum tipo de mediação cognitiva para que ocorra a percepção; e c) que animais são separados do ambiente pela pele.

\section{Estímulo e informação}

Uma visão ecológica foi desenvolvida para tratar da percepção por J. J. Gibson (1986 [1979]) em um sistema de óptica ecológica, que re-descreveu o organismo percebedor e o ambiente percebido de modo que formassem uma unidade. $\mathrm{Na}$ óptica ecológica de Gibson, luz, espaço, movimento e outras propriedades são necessariamente designadas como dependentes do organismo, e o organismo percebedor é descrito como integrado ao ambiente. A percepção de si e do ambiente é então definida como inseparável. Segundo Gibson (1986 [1979]), os domínios aparentemente separados do observador e mundo observado são, na verdade, apenas pólos de atenção.

De acordo com Shaw, Turvey e Mace (1982), no realismo direto, o que percebemos é informação, não estímulo. A diferença entre informação e estímulo fica clara quando analisamos o contexto da informação visual. Gibson (1986 [1979]) classifica a luz em dois tipos: luz radiante e luz ambiente. A primeira diz respeito ao conjunto de raios luminosos que divergem de uma determinada fonte de energia. É percebida olhando-se diretamente para a própria fonte de luz. Nesse caso, a estimulação dos receptores da retina indica apenas a existência da energia luminosa. Mas, quando a luz radiante incide sobre um meio específico, ela é refletida em diferentes intensidades e direções, dando origem à luz ambiente.

Como as superfícies do ambiente variam em relação às suas propriedades (rigidez, densidade, grau de coesão entre as moléculas etc.), elas modificam a 
luz irradiada revelando estruturas específicas. Dessa forma, a luz é estruturada à medida que é refletida, ou seja, ela mapeia a estrutura e as características do ambiente. A refração é um processo que estrutura a energia luminosa, de modo que a luz refletida, ou luz ambiente, deixa de ser só energia e passa a ser informação. É essa informação que especifica as propriedades dos objetos, tais como o formato e a textura da sua superfície. Sendo assim, informação é energia estruturada pelo ambiente e, devido à relação direta entre energia ambiental estruturada e propriedades percebidas, a percepção não exige processos inferenciais. A informação perceptual corresponde aos padrões de energia estruturada em um dado nicho. Tais padrões de energia especificam, de forma precisa e fiel, a existência (e as características) de objetos e eventos que o observador percebe.

Nesse sentido, uma determinada realidade física provoca uma estrutura ou padrão de energia único no ambiente. No caso da informação visual, por exemplo, a cada propriedade que estrutura a luz no ambiente, corresponde uma propriedade óptica única. A energia é estruturada de forma invariante. De acordo com Fonseca et al (2007), há invariantes em todos os tipos de padrões de energia estruturada: na luz ambiente estruturada, nos padrões de vibração das ondas sonoras, padrões de difusão química e também nos padrões de deformação de tecidos biológicos. A existência de uma relação de especificidade entre padrões de energia e estados físicos que configuram esses padrões torna possível a percepção sem a necessidade de qualquer forma de mediação. Há uma relação da especificidade regida por leis naturais entre uma determinada propriedade presente no ambiente (por exemplo, sólido) e um determinado padrão de energia estruturada por essa propriedade, a informação. Nesse contexto, caso exista um observador capaz de detectar essa informação, isto é, o padrão de energia, por meio dos seus sistemas perceptuais, a percepção da propriedade sólido só pode ser direta.

\section{Affordances}

Para que a percepção seja direta, é necessário que uma determinada propriedade do ambiente seja especificada pela informação, ou padrão de energia estruturada, e que o animal observador seja dotado de sistemas perceptuais que o tornem capaz de detectar essa informação. Affordance é o termo criado por Gibson para se referir às possibilidades de ação fornecidas pelo ambiente para um determinado animal. O processo de percepção envolve perceber affordances das superfícies, 
objetos, locais, pessoas e eventos, ou seja, perceber quais possibilidades de ação são permitidas pelo ambiente. As propriedades físicas de uma superfície possibilitam determinadas ações. Uma superfície plana, horizontal, com alta rigidez, por exemplo, oferece affordance de suporte para uma pessoa caminhar. Um determinado objeto pode especificar a affordance "pegável", "manipulável", "rasgável", "dobrável" dependendo da complementaridade entre as propriedades do objeto e as habilidades da mão do observador.

Portanto, perceber uma affordance é perceber a relação entre uma propriedade e o uso dessa propriedade por um ser vivo. Nesse sentido, uma affordance é específica não só para o ambiente, mas também para o ser vivo. Um indivíduo treinado para escalar percebe uma superfície com alto grau de inclinação como escalável, o mesmo não acontece com um indivíduo não treinado. Uma cadeira pode oferecer a affordance sentável, ou seja, pode possibilitar a ação de sentar a um adulto, mas não a uma criança pequena (que pode percebê-la como escalável).

Diferentes layouts especificam diferentes ações para diferentes animais. Portanto, uma affordance se refere tanto ao ambiente quanto ao animal, implicando em uma complementaridade entre ambos. Mas, a percepção de uma affordance não necessariamente implica a sua efetivação. Da mesma forma, a existência de uma affordance independe da presença de um observador, uma vez que uma affordance se refere àquilo que o ambiente oferece e não só àquilo que o animal observa. A percepção de uma affordance só é possível se o indivíduo possuir as características que lhe permitam perceber e fazer uso dessa affordance.

\section{Informação perceptual e informação linguística}

De acordo com Duque (2015b), a dinâmica do homem no ambiente equivale ao conjunto das ações que ele executa. Nesse sentido, o ato de escalar uma árvore, por exemplo, é ação e significado ao mesmo tempo. É sobre essa condição semântica inicial que elaboramos significados cada vez menos corporificados: por exemplo, é sobre a ação de empilhar coisas semelhantes (por cor, tamanho, formato etc.) que desenvolvemos a noção de categoria conceptual.

Os eventos do mundo são definidos em termos da sua dinâmica física subjacente. Por exemplo, duas situações de bola quicando são exemplos de um mesmo tipo de evento: BOLA-QUICANDO porque a dinâmica envolvida no movimento é a mesma em ambos os casos. As duas instâncias podem até ser 
diferentes em relação aos seus parâmetros (por exemplo, a altura inicial da bola), mas, mesmo assim, são exemplos do mesmo evento no mundo. Eventos como esse criam informação: a luz refletindo sobre a bola quicando é estruturada de acordo com as leis da óptica ecológica para o movimento específico daquela bola. Esse fluxo óptico é específico ao evento em questão e qualquer organismo que detecte esta informação pode, portanto, perceber diretamente o evento no mundo. $\mathrm{O}$ significado da informação, neste caso, é a própria dinâmica do evento no mundo, e é este significado que o organismo deve apreender.

$\mathrm{O}$ fato de o organismo poder usar esta informação para controlar com sucesso seu comportamento é uma evidência de que o organismo tem acesso a este significado. Segundo Wilson e Golonka (2013), a fala em si é um tipo de evento (ou melhor, é uma série de eventos interconectados). O evento de fala estrutura uma matriz acústica de acordo com as leis da acústica ecológica. Essa estrutura é específica para o evento da fala e qualquer organismo que detecte essa estrutura pode, portanto, perceber diretamente o evento de fala. Mas neste caso, o significado da informação não é a dinâmica da articulação da palavra em si. O significado que o organismo deve apreender é o significado convencional da palavra pronunciada.

A diferença entre a percepção de uma bola quicando e a fala está em como a informação significa. No caso da bola quicando, o fato é que o padrão de fluxo óptico que significa BOLA QUICANDO está subscrito pelo processo legitimado pelo movimento da bola que foi projetado para dentro da matriz óptica, e a forma da informação, portanto, se relaciona ao evento subjacente. Para o evento da fala, o fato é que o padrão da matriz acústica que significa, por exemplo, BOLA não está subscrito por um processo legitimado. Dentro desse enquadre, o termo informação perceptual diz respeito à informação cujo significado está subscrito por um relacionamento de especificação: a informação auditiva é sobre sons, a informação visual é sobre propriedades visuais do ambiente. A audição da palavra "cão", entretanto, não é apenas um ato de percepção, porque ouvir uma palavra envolve a apreensão da estrutura numa matriz de energia, desde que o significado da informação esteja subscrito por um relacionamento convencional entre a informação e o mundo.

Diferentemente da informação perceptual, de acordo com Wilson e Golonka (2013), a informação linguística (em qualquer modalidade em que seja transportada), portanto, é sobre significados convencionais de eventos linguísticos, que devem se referir a sons, visões, ideias etc. Os eventos auditivos da fala dizem 
respeito a significados convencionais de eventos linguísticos, em vez de atos físicos de articulação da fala. A linguagem é um meio em si que permite o fluxo da informação linguística por meio das modalidades som, visão ou toque.

Seres-humanos fazem adaptações que os ajudam com o problema do significado linguisticamente orientado. Segundo Tomasello (2008), somos muito bons em compartilhar atenção voltada para alguma coisa do ambiente, da mesma forma que somos, também, motivados a nos comunicar com os outros.

\section{Frames}

Como vimos, as informações linguística e perceptual ocupam diferentes nichos num espaço de tarefa. Conforme Wilson e Golonka (2013), enquanto a informação perceptual nos ajuda, por exemplo, a caminhar e pegar uma bola no ar, a informação linguística nos ajuda a expandir a variação do conhecimento sobre o ambiente, tendo em vista que a informação perceptual é limitada ao espaço e ao tempo. Além disso, a informação linguística nos possibilita realizar ações que não existem sem a linguagem, como celebrar um casamento ou expedir uma sentença judicial.

De acordo com Goffman (1974), como somos incapazes de compreender plenamente as complexidades do mundo, nós nos baseamos no framing para classificar, gerenciar e interpretar experiências perceptuais e motoras. Acionadora desse mecanismo, a informação linguística nos leva a construir significados e a adotar visões de mundo. Em suma, o framing é um processo linguístico por meio do qual as pessoas desenvolvem uma conceptualização específica ou reorientam seu pensamento sobre um problema.

Tal mecanismo pressupõe que sejam realizadas múltiplas descrições do mesmo evento e que tais diferenças de descrição tenham implicações na formação de significados e crenças. Por exemplo, a expressão "alívio de impostos 1 " (LAKOFF, 2004, p. 3) funciona ideologicamente construindo uma visão de mundo específica em que a tributação é enquadrada como um peso que precisa ser aliviado. $\mathrm{O}$ autor defende que quando "impostos" são relacionados a "alívio", a pessoa responsável pelo alívio passa a ser um herói, e a que cria ou mantém os impostos passa a ser um vilão. 
De acordo com Lakoff (2012, p. 773), “[...] o pensamento é físico e é transportado por circuitos neurais funcionais" ${ }^{\mathrm{e}}$ "[...] frames são circuitos neurais inconscientes [...]"3(LAKOFF, 2013). Frames podem ser organizados em sequências, padrões ou redes. Nesse sentido, a progressão de um leitor durante a leitura de um texto pode ser comparada com uma navegação simultânea de uma rede de conhecimentos estruturada por frames. Por exemplo, em "ele ganhou uma boa gorjeta", a palavra "gorjeta" ativa a experiencia de uma pessoa dando dinheiro a outra pessoa, possivelmente, em um restaurante. Uma pessoa que ouve, lê ou vê a sinalização da palavra "gorjeta" pode inferir que alguém solicitou algo para comer, comeu, pagou e deu dinheiro adicional para o garçom. A quantidade de gorjeta pode também ser inferida. Como regra, é menor que o preço real da refeição e, em alguns países, pode ser calculada como um percentual do custo da refeição (no Brasil, 10\%). O método de apresentação pode variar de país a país. Normalmente, a gorjeta é deixada na mesa junto com o pagamento. No Brasil, o costume é realizar o pagamento e dizer ao garçom para ficar com o troco.

O frame RESTAURANTE acessado pela palavra "gorjeta" inclui o conhecimento de sequências convencionais de eventos, ações, estados e processos que podem ser usados com sequências de palavras e construções para impor ordem aos textos. O item "gorjeta" do frame é vinculado a uma estrutura global que nos possibilita a processar o discurso de forma incremental. Esse mecanismo global (ou evento) é abstraído da experiência, tendo sido simultaneamente internalizado e rotulado como uma atividade condicionada por membros da comunidade em atividades de engajamento colaborativo (TOMASELLO, 2008).

Frames (ou partes de frames) são indexados por palavras, mas um frame não mantém uma relação de hierarquia com as suas partes, mas sim de domínio cognitivo. Para melhor esclarecer isso, vamos utilizar os exemplos clássicos de Fillmore (1977): o frame TRANSAÇÃO COMERCIAL e o frame TRANSFERÊNCIA DE VALORES. Os componentes ${ }^{4}$ do frame TRANSAÇÃO COMERCIAL são: comprador, vendedor, mercadoria e dinheiro. De acordo com o autor, há um conjunto de indexadores linguísticos relacionados a esse frame: "comprar", "vender", "pagar", "custar", "gastar" e "cobrar", e cada um deles indexa (ou aciona) aspectos distintos do frame. O verbo 'comprar', por

2 "[...] thought is physical and is carried out by functional neural circuitry".

3 "[...] frames are the unconscious neural circuits [...]"

4 Cumpre esclarecer que estou me referindo aqui a atributos situacionais, não a papéis semânticos: agente, paciente, tema etc. 
exemplo, focaliza o comprador e a mercadoria, deixando o vendedor e o dinheiro no background (fundo) da cena (esses atributos são facilmente recuperados por inferência). Já o verbo 'pagar' focaliza o comprador, o dinheiro e o vendedor, deixando a mercadoria comprada de fundo.

Conhecer o significado de um verbo relacionado ao frame TRANSAÇÃO COMERCIAL, por exemplo, exige conhecer os componentes desse frame, ou seja, conhecer o significado de um verbo relacionado a esse frame implica o conhecimento do significado de todos os demais. O conhecimento e a experiência estruturados pelo frame TRANSAÇÃO COMERCIAL fornecem o background e a motivação para as categorias das palavras. Como vimos, por exemplo, a partir do uso da palavra "pensão", além das informações acionadas diretamente, há outras informações envolvidas nesse domínio, incluindo as negociações em juízo, decisões judiciais etc. Isto é, as palavras ativam cenas inteiras. Ao considerarmos a sentença "Na igreja, ela disse sim emocionada", embora não haja menção a uma cerimônia de casamento, compartilhamos um fundo cultural que ativa um evento de CASAMENTO. De modo geral, frames constituem circuitos neurais que orientam a maneira como construímos a percepção indireta dos eventos e podem ser pensados como mecanismos cujos componentes estabelecem relações entre si formando uma estrutura reticulada.

\section{a. Dimensões do frame}

Segundo Duque (2015a), quanto à complexidade, frames podem ser extremamente simples, contendo poucos papéis e poucas relações entre esses papéis, reduzindo-se a meros esquemas de imagem (esquema-I) ou invariantes perceptuais armazenadas na memória. $\mathrm{O}$ autor propõe uma classificação pensada em termos de possíveis ângulos a serem adotados ao analisarmos informações linguísticas em discurso. Para fins meramente didáticos, baseado em Fillmore (1977) e Fillmore (1982), categorizo aqui os frames em dois grupos: frames linguísticos e frames interacionais.

\section{b. Frames linguísticos}

Frames linguísticos não só refletem os padrões cognitivos de distribuição social na distribuição do material linguístico. Eles também podem conter implicações abertas aos cenários interacionais em que os itens linguísticos são usados. Para 
fins metodológicos, apresento seis dimensões dos frames linguísticos: dimensão esquemática, dimensão conceptual básica, dimensão do evento, dimensão do roteiro, dimensão do domínio específico, dimensão sociocultural.

\section{a. Dimensão esquemática do frame}

Em linhas gerais, Lakoff (1987) e Johnson (1987) caracterizam esquemas imagéticos (esquemas-I) como modelos cognitivos configurados como estruturas conceptuais significativas fundamentadas no deslocamento do corpo no espaço, nas interações perceptuais e na manipulação de objetos; organizados como esquemas de invariância das experiências perceptuais e motoras, a partir da captura de informações perceptuais de múltiplas modalidades (visão, audição, paladar etc.); situados abaixo da consciência, anteriores e independentes de outros conceitos; estruturados internamente, ou seja, são compostos de poucas partes relacionadas; flexíveis e que manifestam sua flexibilidade por meio de transformações em contextos pragmáticos distintos.

A partir dessas características, podemos afirmar que as invariâncias da informação perceptual constituem a base da organização do conhecimento e de raciocínio no/sobre o mundo. Eventos e roteiros diferentes como CAMINHAR PARA O SUPERMERCADO ou PROCURAR LEITE NA PRATELEIRA, por exemplo, exibem a mesma estrutura esquemático-imagética: no caso, revelam uma trajetória com um ponto de chegada específico. ${ }^{5}$

A variedade de sentidos que atribuímos a nossas experiências cotidianas parece se fundamentar em esquemas-I enquadrados e combinados de diferentes maneiras. Os frames GARRAFA e SUPERMERCADO, por exemplo, diferem obviamente em inúmeros aspectos, mas são equivalentes do ponto de vista esquemático-imagético: ambos são construídos sobre o esquema-I CONTÊINER, pois apresentam limite, dentro-fora, superficie, cheio-vazio, conteúdo e portal. No entanto, apesar de os frames GARRAFA e SUPERMERCADO se estruturarem sobre o mesmo esquema-I CONTÊINER, para cada caso, ocorre a combinação de esquemas distintos e/ou de diferentes maneiras: tanto em GARRAFA quanto em SUPERMERCADO, por exemplo, os componentes cheio-vazio integram também o esquema-I QUANTIDADE. No entanto, em GARRAFA, o esquema-I QUANTIDADE se integra com o esquema-I VERTICALIDADE na constituição

5 De acordo com Dodge e Lakoff (2005), ao analisarmos sentenças que descrevem movimento de uma pessoa, como é o caso desses dois exemplos, a sequência temporal básica de mudança de localização do trajetor é expressa usando a estrutura esquemática ORIGEM-CAMINHO-META. 
do esquema menos imagético ${ }^{6} \mathrm{ESCALA}$, isto é, à medida que o conteúdo do interior do CONTÊINER se desloca pelo portal, do interior para o exterior, a QUANTIDADE do líquido diminui. Essa diminuição gradual pode ser capturada pelo rebaixamento gradativo da superfície do líquido na garrafa, formando a noção de ESCALA. Em SUPERMERCADO, o esquema I QUANTIDADE não parece se integrar com o esquema-I VERTICALIDADE. Logo, no que diz respeito à QUANTIDADE, normalmente não acionamos o conteúdo de SUPERMERCADO, ou seja, clientes e produtos por meio de expressões como "subir" ou "descer", como fazemos em relação ao conteúdo de GARRAFA.

Há quatro mecanismos básicos de construção da estrutura reticulada do frame por meio da combinação de esquemas imagéticos: constituência, subcategorização, evocação e unificação.

- Constituência: esquemas complexos são estruturados por esquemas simples. O frame ENTRAR, por exemplo, é constituído dos esquemas-I TRAJETOR-MARCO, ORIGEM-CAMINHO-META e CONTÊINER integrados pela equivalência dos componentes meta (do esquema-I ORIGEM-CAMINHO-META) e interior (do esquema-I CONTÊINER) e marco (do esquema-I TRAJETOR-MARCO);

- Subcategorização: esquemas são organizados em hierarquias e cada nível de inclusão é induzido por uma relação de subcaso entre um esquema e sua estrutura mais genérica (ou o conjunto dessas estruturas). Os frames SUPERMERCADO e GARRAFA, por exemplo, são subcasos do esquema-I CONTÊINER;

- Evocação: esquemas podem evocar estruturas de fundo (frames ou esquemas de base) sem que isso implique qualquer relação de herança (subcategorização) ou constituência. Essa subespecificação fornece a flexibilidade necessária para a construção de especificações semânticas. No frame ENTRAR, por exemplo, o esquema-I TRAJETOR-MARCO evoca o componente meta do esquema-I ORIGEM-CAMINHO-META que, por sua vez, evoca o componente interior do esquema-I CONTÊINER. No caso do esquema SAIR, embora a constituência fosse a mesma de ENTRAR, as evocações seriam diferentes.

6 Diz respeito à capacidade para a metáfora conceitual, que nos permite projetar a estrutura experimental dos domínios "imagéticos" da experiência sensório-motora em estruturas não imagéticas ("mais abstratas"). Os esquemas-I são como âncoras corporificadas de todo o sistema conceitual, do menos ao mais abstrato. 
- Unificação: trata-se da etapa da construção do sentido em que os componentes que integram um esquema são preenchidos por elementos do contexto situacional ou discursivo.

Para sermos coerentes com a perspectiva de corporalidade assumida neste artigo, uma maneira de começarmos a examinar mais detidamente esquemas-I é realizando a descrição fenomenológica dos componentes estruturais mais básicos da experiência corporificada de percepção (e de movimento) dos humanos, considerando que compartilhamos várias capacidades sensório-motoras básicas (de acordo com as dimensões e constituição dos nossos corpos) e características comuns dos diferentes ambientes em que vivemos.

\section{b. Dimensão conceptual básica do frame}

Frames são indexados diretamente por itens ou expressões lexicais individuais. Os componentes do frame são interconectados tão fortemente que cada conceito específico só pode ser definido em relação à estrutura reticulada completa. Em termos da construção incremental do sentido no discurso, o fato de itens lexicais simples indexarem frames completos possibilita a realização de inferências, sem que seja necessário apresentar um conjunto exaustivo de itens e expressões lexicais. Normalmente, durante a visualização ou audição do texto, um item lexical ou expressão nominal ativa o frame conceptual básico que, aos poucos, vai sendo reforçado, delineado e perspectivado pelo acionamento de regiões específicas da estrutura reticulada.

\section{c. Dimensão de evento do frame}

A dimensão conceptual básica fornece os conceitos, mas é a dimensão do evento que indica que tipos de relação são estabelecidos entre os conceitos acionados. Eventos, aqui, são concebidos como estados e ações que constituem uma cena. Descrever eventos exige a identificação de estados prévios à realização da ação e os estados resultantes da ação. A descrição do evento exige a observância aos seguintes aspectos dessa dimensão:

- Caracterização do tipo do evento: os eventos devem ser categorizados a partir do tipo de ação executada. As ações mais básicas são a de deslocamento físico, de percepção e de manipulação de objetos. O deslocamento físico pode ser autopropulsionado (como em João foi para casa) ou provocado por um agente (como em João derramou o leite no chão). O deslocamento 
físico provocado pode envolver transferência de coisas (como em João entregou o presente à aniversariante). A manipulação pode provocar alterações no objeto manipulado (como em João amassou o papel) ou não (como em João segurou o livro).

- Identificação do esquema de ação (Esquema-X): esquemas-X fornecem os slots do evento a serem preenchidos por elementos do contexto pragmático ou discursivo. Em CORRER e COMPRAR, são necessários respectivamente o CORREDOR e o COMPRADOR. Cumpre esclarecer que outros slots podem ser ativados pelo esquema-X, como por exemplo, em CORTAR, além do CORTADOR e do CORTADO, pode ser evocado o INSTRUMENTO. Estados prévios e resultantes da ação normalmente são preenchidos por elementos default, como em SENTAR, cujo estado prévio, por default, é ESTAR DE PÉ.

- Identificação dos preenchedores: elementos do contexto pragmático ou discursivo que subcategorizam os elementos default que preenchem os slots ativados pelo esquema-X. Por exemplo, em CHUTAR, CHUTADOR e CHUTADO podem ser subcategorizados respectivamente por NEYMAR e BOLA.

- Verificação dos ajustes temporais e espaciais: instante (ou período) e CENÁRIO da ação. Normalmente, os ajustes temporais e espaciais são acionados por indexadores como "na segunda-feira", "naquele dia", "no circo" etc., ou acionados por inferência na estrutura reticulada da dimensão conceptual básica do frame, como por exemplo, a partir do enunciado "depois que a noiva disse "sim', eu tive que sair", "noiva" e " disse 'sim"” ativam o frame CASAMENTO e, by default, o cenário IGREJA.

- Caracterização do segmento discursivo: o segmento discursivo é associado ao frame interacional, com a categoria discursiva (RECEITA, AULA, ROMANCE etc.), o assunto do enunciado (POLÍTICA, FÉRIAS, COMPRAS etc.) e o ato de fala (declararivo ou interrogativo, por exemplo).

\section{d. Dimensão de roteiro do frame}

Roteiros constituem eventos estruturados cronologicamente. São estruturas de conhecimento que delineiam como os eventos do dia a dia se desdobram e organizam algoritmicamente o nosso conhecimento sobre procedimentos. Sequências de ações que caracterizam eventos experienciados com frequência 
guiam nossas expectativas e formatam comportamentos em situações cotidianas. Em outras palavras, a experiência recorrente de um determinado evento pode criar um molde internalizado da provável sequência de ações, participantes e entidades dentro da situação experienciada. Por nos guiar na elaboração de inferências sobre os eventos seguintes, quebras de expectativa são compensadas com sensações de humor, ansiedade, tristeza etc. O frame CASAMENTO, por exemplo, dentre outras coisas, ativa o roteiro de eventos específicos de um casamento.

\section{e. Dimensão de domínio específico do frame}

Certos conceitos são evocados por frames de domínios conceptuais bem específicos (JUSTIÇA, RELIGIÃO, POLÍTICA PARTIDÁRIA, ECONOMIA etc.). Esses frames, muitas vezes, entram em conflito com frames de domínio do senso-comum. Por exemplo, ASSASSINO e INOCENTE orientam uma construção de sentido específica no domínio da justiça. Nesse domínio, há uma diferença fundamental entre HOMICÍDIO-DOLOSO (matar alguém de forma premeditada) e HOMICÍDIO-CULPOSO (matar alguém acidentalmente). Nesse domínio, noções como INOCENTE e CULPADO são preenchidas no frame JULGAMENTO, em que pessoas podem ser inocentes mesmo que tenham matado alguém. Fora desse domínio, normalmente as pessoas acionam o frame ENVOLVIMENTO NO CRIME; e este frame não contempla INTENCIONALIDADE em sua estrutura.

\section{f. Dimensão sociocultural do frame}

A dimensão sociocultural do frame desempenha o papel de orientar comportamentos e expectativas sociais e culturais, mas pode também enquadrar pessoas e grupos em categorias sociais e culturas idealizadas e generalizadas, a partir de padrões típicos de comportamento, aparência, orientação sexual, etnia etc.

Tal dimensão é modelada por princípios morais, uma vez que diz respeito aos grupos sociais, o papel dos indivíduos e a conexão entre esses indivíduos. De acordo com Lakoff (1995), relações sociais são concebidas em termos de TRANSFERÊNCIA, isto é, eventos em que pessoas transferem “coisas" umas para as outras pessoas. A coisa transferida pode ajudar o receptor, causando-lhe bemestar, ou prejudicá-lo, causando-lhe mal-estar. Nesse sentido, para o autor, a ação moral parece ser conceptualizada em termos de transação contábil. Entendemos o aumento de bem-estar como "ganho" e a diminuição do bem-estar como "perda". 
Segundo Lakoff (1995), da mesma forma que a contabilidade tomada de forma literal é vital para o funcionamento econômico, a contabilidade moral é vital para o funcionamento social. E, da mesma forma que é importante que os lançamentos financeiros, débito e crédito, estejam equilibrados, é fundamental que os lançamentos morais também o sejam. O domínio fonte da metáfora de operações contábeis, em si, possui uma moral: pagarmos nossas dívidas é moral; não pagarmos nossas dívidas é imoral. Segundo o autor, quando a ação moral é entendida metaforicamente em termos de operação contábil, o campo das finanças é projetado no campo da moralidade em geral: dívidas financeiras são dívidas morais.

Dessa forma, interações sociais podem causar bem-estar ou mal-estar aos envolvidos. Cada transação é estruturada pelo esquema-I EQUILÍBRIO, ou seja, se $\mathrm{A}$ faz algo de bom a B, então B precisa fazer algo de bom a A (pois, B está em débito com $\mathrm{A}$ ). Se $\mathrm{B}$ faz algo de bom a $\mathrm{A}$, então $\mathrm{A}$ terá sido reembolsado e o equilíbrio é mantido. Segundo Lakoff (1995), as palavras do domínio da contabilidade são usadas normalmente para falarmos de moralidade:

(1) Ele está me devendo por ter feito eu passar vergonha em público.

(2) Tenho uma dívida de gratidão com ele.

(3) Você vai me pagar por ter falado aquelas coisas.

(4) Ele perdeu muitos pontos comigo.

Segundo Lakoff (1995), a moralidade não é de todo metafórica. O sistema metafórico se baseia em aspectos não metafóricos da moralidade. A moralidade não metafórica é sobre a própria experiência de bem-estar. A forma mais básica de moralidade, nesse sentido, diz respeito à promoção do bem-estar, ao impedimento e à prevenção de danos experienciais aos outros. Parte do que se entende por bemestar é ser saudável em vez de doente, ser rico em vez de pobre, ser forte em vez de ser fraco, ser feliz em vez de ser triste ou revoltado, ser limpo em vez de ser sujo, ser bonito em vez de ser feio, estar na luz, não no escuro, ficar de pé, não deitado etc. Os opostos constituem formas de danos. Uma ação imoral é aquela que priva alguém de saúde, riqueza, felicidade, força, liberdade, segurança, beleza etc.

Em geral, essas condições e experiências de bem-estar estão diretamente relacionadas. De acordo com o autor, tais condições fundamentam o nosso sistema de metáforas morais. Por exemplo, se BEM-ESTAR É RIQUEZA, a contabilidade moral se baseia no conhecimento de que é melhor ser rico do que ser pobre; se BEM-ESTAR É RESISTÊNCIA, a contabilidade moral se baseia no conhecimento 
de que ser resistente é melhor do que ser fraco; se BEM-ESTAR É SAÚDE, a contabilidade moral se baseia no conhecimento de que é melhor termos saúde do que sermos doentes etc. Logo, a metáfora da moralidade é fundamentada na moralidade não metafórica, ou seja, nas formas de bem-estar, e que o sistema de metáforas para a moralidade como um todo, portanto, está longe de ser arbitrária.

Como as mesmas formas de bem-estar são comuns em todo o mundo, é de se esperar que as mesmas metáforas para moralidade se mostrem em várias culturas - e elas o fazem. Onde encontramos rituais de purificação, encontramos manifestação de moralidade como pureza; por causa do medo generalizado da escuridão, encontramos uma concepção generalizada de mal como escuro e bem como luz; como é melhor se manter de pé, erguido, do que tropeçar e cair, encontramos a metáfora generalizada de que moralidade é estar ereto.

\section{c. Frame interacional}

Diferentemente do frame linguístico, o frame interacional ocorre apenas a partir de interações sociais mediadas pela linguagem, ou seja, interações que evocam frames modelados com base na compreensão da situação comunicativa em si. O frame interacional diz respeito à forma como conceptualizamos o que acontece entre o falante e o ouvinte, ou entre o autor e o leitor, quando interagem comunicativamente uns com os outros. O frame interacional, desse modo, constitui a ferramenta de uso de frames linguísticos e expectativas levadas pelos interlocutores para dar suporte à compreensão e produção do discurso oral e escrito, especialmente com relação aos exemplos de categorias textuais. Fillmore (1982) parte do pressuposto de que o conhecimento da categoria textual, por exemplo, se contrato comercial, conto folclórico ou proposta de casamento desencadeia o emprego de estratégias de compreensão específicas, as quais favorecem uma interpretação bem-sucedida. De acordo com Fillmore (1976), esse tipo de frame associado à comunicação inclui o conhecimento das intenções do falante/escritor e as rotinas de eventos de fala, o que contribui para a compreensão do intercâmbio conversacional.

Fillmore (1976) cita, como um caso comum, o frame CUMPRIMENTO, que apresenta grande variação de cultura para cultura. A forma textual específica de um cumprimento e sua resposta complementar é selecionada de um inventário restrito de tópicos e expressões e são normalmente determinadas por condições contextuais 
muito específicas. Para Neubert e Shreve (1992, p. 62), muitos cumprimentos são puramente interacionais: "como vai? ", "oi", "olá", "bom dia" na verdade são nada mais do que sinais funcionando como um tipo de "argamassa social" para a comunicação fática. De acordo com os autores, para sondarmos mais a fundo a matriz social de cumprimentos, com seus nomes, títulos e outras formas de direção, precisamos dar conta de uma variedade de distinções conceptuais envolvendo papel social e estratificação social. Logo, precisamos recorrer a frames linguísticos. Devemos considerar, por exemplo, como a passagem do tempo determina o acesso ao frame CUMPRIMENTO: "bom dia", "boa noite" e "boa tarde".

É, portanto, possível usar o conceito de frame interacional para explicar a categorização e a distribuição social de formas textuais. Um cumprimento não é menos texto que um manual de instrução, um contrato legal ou uma patente industrial. Todos são formas de interação estruturadas com conteúdos perceptíveis usados sob condições contextuais específicas. Frames interacionais fornecem receitas para produzir e decodificar textos. Esses textos são modelos a partir dos quais indexadores de frames linguísticos são injetados (pelo falante / escritor) e a partir dos quais indexadores linguísticos de frames conceptuais podem ser extraídos (pelo ouvinte / leitor). A distinção é estruturalmente útil, mas pode não ser psicologicamente real. Independentemente de seus conteúdos, frames podem ser considerados como padrões de conceptualização e interação socialmente distribuídos e integrados na realidade social usando a linguagem.

Os itens lexicais em textos, normalmente, indexam muitos frames diferentes; o texto cria uma estrutura de associação que é uma estrutura composta compreendida de todas as regiões do frame referenciadas pelo texto. O texto serve como um mecanismo organizacional, estabelecendo ligações reais entre conteúdos de frame cuja associação prévia era só potencial. Associações virtuais são convertidas em associações reais usando mecanismos textuais.

Muitas das estruturas narrativas discutidas por Lakoff(2008) se encaixam nessa categoria de frame. Frames interacionais orientam a nossa conduta e as nossas expectativas no discurso. Um exemplo citado por Lakoff, é o frame DEBATEPOLÍTICO, fundamentado nos clássicos programas de debate na TV e no rádio. Esse frame contém dois ou mais DEBATEDORES, de visões antagônicas sobre um determinado assunto, que, a cada troca de turno, fornecem suas respectivas OPINIÕES enquanto tentam invalidar os ARGUMENTOS um do outro. O debate 
é orientado por um MODERADOR, que normalmente fica localizado entre os debatedores oponentes. O DEBATE-TELEVISIVO é normalmente estruturado em uma sequência de ASSUNTOS, cuja progressão é orientada pelo moderador.

\section{Conceitos mais abstratos}

Lakoff (1987) defende que a imagética inicial (esquema imagéticos, para o autor) pode se estender metaforicamente a domínios mais abstratos. Dentro desse enquadre, a noção de CONTÊINER, por exemplo, é esquematizada com base na experiência direta de que um contêiner apresenta um dentro e um fora e que um objeto pode estar dentro ou fora de outro, mas nunca dentro e fora ao mesmo tempo. Essa percepção direta de contêineres e de suas affordances seria a base, de acordo com o autor, para a nossa compreensão de um princípio lógico estruturado como "p ou não-p, mas não ambos." Na visão de Barsalou (1999), a simulação é criada a partir de situações experienciadas no cotidiano que, com o tempo, vão sendo refinadas pela linguagem. Sendo assim, a noção de contêiner emergiria da experiência com exemplos específicos de recipientes, ou seja, usamos a linguagem baseados em situações concretas nas quais affordances são identificadas. Nesse sentido, pode ser que a abstração emerja de múltiplos exemplos. O conceito de DEMOCRACIA, por exemplo, parece emergir, em grande parte, de experiências específicas (em primeira ou terceira pessoa) envolvendo o ato de votar.

É claro que uma compreensão mais sofisticada da noção de "democracia" envolve muito mais do que isso. No entanto, essa sofisticação parece estar baseada em exemplares múltiplos, da mesma forma que a compreensão sofisticada sobre CADEIRA inclui CADEIRAS DE JANTAR, CADEIRAS ESTOFADAS, CADEIRAS DE BALANÇO etc. Em suma, a compreensão de ideias abstratas tem relação com o uso de exemplos concretos em todos os níveis de aprendizagem. Mas como isso ocorre?

Como vimos acima, o ser humano aciona seus sistemas perceptuais e motores durante o processo de compreensão linguística sobre coisas que vê ou ouve. Nesse processo, as pistas linguísticas parecem orientar as simulações. Uma característica da informação linguística, que a diferencia de outras informações perceptuais, é que podemos usá-la para tratar de coisas e ações não percebidas e não executadas no ambiente de entorno de quem fala e ouve. Mas que simulações mentais estariam sendo produzidas por indexadores linguísticos como "amor", "solidão" e "sociedade"? 
Indexadores linguísticos como esses - sobre conceitos abstratos - apresentam um obstáculo para a noção de que compreensão é simulação. Como podemos acionar simulações mentais a partir de enunciados sobre coisas que não parecem ser capturadas pelos órgãos sensoriais? Para verificar como ocorre a compreensão de sentenças sobre conceitos abstratos, selecionei algumas ocorrências de palavras que nos remetem a noções intangíveis fisicamente, como SOCIEDADE. Para entender como as pessoas usam o item linguístico "sociedade", utilizei o mecanismo de busca Google e verifiquei como elas falam de sociedade.

(14) Entre os mecanismos alienantes da economia e as limitações opressoras do poder, o Homem reage infiltrando, nas fendas da sociedade, formas de vivencias revitalizadoras para recuperar seu sentido de participação e construção de identidade. (http://www.plurall.com, em 06/10/2011).

(15) Atualmente a nossa sociedade se abriu para uma grande discussão no âmbito educacional. (www.webartigos.com, em 06/10/2011).

(16) Sempre presentes na história da humanidade, as epidemias continuam a interferir no comportamento das pessoas, trazendo medo e preconceito para dentro da sociedade. (psiquecienciaevida.uol.com.br, em 06/10/2011)

Apesar de não termos noção de como a sociedade é fisicamente, que cheiro tem ou que som emite, somos capazes de compreender os enunciados (14), (15) e (16). Ao analisar mais detidamente os trechos selecionados, verifiquei que o modo como (14), (15) e (16) se referem à sociedade é semelhante ao modo como falamos de coisas concretas: que possuem fendas por onde passam coisas; que podem ser abertas e onde objetos podem ser introduzidos. Mesmo sem uma análise mais profunda, esses exemplos evidenciam que tratamos a sociedade como se ela fosse uma espécie de recipiente que possui "fendas", que pode "ser aberto" e que tem "um interior", onde podemos "depositar coisas". Em minha rápida investigação, identifiquei outras maneiras de compreender sociedade. Sociedade pode ser um corpo, como em (17), (18) e (19):

(17) O arroz representava a espinha dorsal econômica da sociedade samurai. (www.aikikai.org.br, em 06/11/2011)

(18) Hoje, o que mutila a sociedade é a desagregação da família e o enfraquecimento dos seus valores. (www.psdc.org.br, em 06/11/2011).

(19) Esse video que estou postando junto é de uma banda que gosto muito, e mostra as mentes e os braços da sociedade. (sociologiass-unesp.blogspot.com, em $06 / 11 / 2011$ ) 
O uso sistemático de enunciados que normalmente descrevem uma coisa concreta (como um recipiente ou o corpo) para descrever uma coisa abstrata (como SOCIEDADE) é conhecido como metáfora. Por exemplo, em "trazendo medo e preconceito para dentro da sociedade" alguma coisa se move para dentro de um recipiente, por meio de uma abertura. Isso nos leva a simular um movimento físico descrito pelo enunciado. Em outras palavras, realizamos simulações motoras e perceptuais mesmo quando processamos enunciados metafóricos.

\section{Considerações Finais}

Neste artigo procurei caracterizar uma possível abordagem ecológica de cognição e linguagem. Para isso, demonstrei que abordagens de percepção pautadas no realismo indireto (racionalista ou experiencialista) repercutem na forma como concebemos corporalidade, pois isolam o organismo do ambiente e pressupõem que a percepção seja fruto de processos internos e de representações mentais. Ao defendermos que a percepção é direta, ou seja, sem nenhum processo interno ou mental, passamos a lidar com informações perceptuais, ou seja, padrões de energia estruturada em um dado segmento ambiental. Esses padrões de energia especificam, de forma precisa e fiel, a existência (e as características) de objetos e eventos que o observador percebe.

Ao perceber a relação entre as propriedades dos objetos e eventos e as possibilidades de uso dessas propriedades os organismos extraem affordances do ambiente. Dessa forma, uma affordance é específica não só para o ambiente, mas também para o ser vivo, pois se refere tanto ao ambiente quanto ao animal, implicando em uma complementaridade entre ambos. A dinâmica de um animal em seu ambiente equivale ao conjunto das ações que ele executa. Nesse sentido, ação e significado são equivalentes entre si. Essa parece ser a condição semântica inicial sobre a qual elaboramos significados menos corporificados, em que o significado da informação perceptual é a própria dinâmica do evento percebido.

$\mathrm{O}$ fato de que o organismo usa a informação perceptual para controlar seu comportamento evidencia que o organismo acessa este significado. No caso da informação linguística, construída sobre a informação perceptual, o significado da informação não é a dinâmica da articulação da palavra em si. O significado a ser aprendido pelo homem é o significado convencional da palavra pronunciada. Logo, informação perceptual e informação linguística diferem em relação ao modo como o significado é construído. 
No caso da informação linguística, os sentidos são construídos em meio à interação social. Ela nos ajuda a ampliar o conhecimento sobre o ambiente, pois não se limita ao espaço e ao tempo. Desenvolvemos conceitos e reorientamos nossos pensamentos sobre o mundo por meio de um mecanismo conhecido como framing, isto é, o recurso discursivo-cognitivo de que dispomos para (re)modelar circuitos neurais (ou frames). Um frame linguístico pode ser perspectivado de vários ângulos: do ângulo de sua esquematização inicial pautada nas invariantes derivadas da percepção direta; do ângulo de como os conceitos se formam e se interconectam; do ângulo de como esses conceitos se organizam em eventos e roteiros; do ângulo sociocultural da formação das instituições sociais e de visões de mundo constituídas por metáforas morais. O frame interacional, por sua vez, é modelado pelas interações sociais mediadas pela linguagem. Até mesmo a compreensão de ideias abstratas tem relação com o uso de exemplos concretos em todos os níveis de aprendizagem, pois realizamos simulações motoras e perceptuais mesmo quando processamos enunciados abstratos.

Embora a corporalidade tenha conquistado certa projeção nas últimas décadas, o cérebro e a mente ainda desempenham os papéis principais da cognição. Essa visão se opõe à perspectiva ecológica aqui defendida: a de que a cognição é distribuída para além do cérebro e se estende para além do corpo. E que o cérebro é um recurso de modelagem de dispositivos de execução de tarefas específicas. Esses dispositivos envolvem habilidades do nosso sistema percepto-motor e propriedades de ancoragem complementar do corpo (por exemplo, a mão humana e suas configurações, a escala do corpo etc.) em interação com as propriedades físicas e oportunidades de comportamento fornecidas pelo ambiente. Grande parte do tempo, nossa atuação no ambiente não exige dispositivos sofisticados e complexos. Exige apenas a homeostase do corpo em integração com o ambiente. 


\title{
From Perceptions to Frames: Ecological Cognition and Language
}

\begin{abstract}
This paper posits an ecological approach to cognition and language, by demonstrating that conceptualization processes seem to emerge from the organism-environment interaction. Such cognitive approach relies on the coordination of the two extremes of this emergence and the premise according to which the use of language inevitably involves both the initial interaction processes of the organism with the environment, as well the structures and processes that arise from these interactions. According to the approach here suggested we develop concepts and redirect our thoughts about the world through a mechanism known as framing, i.e., the discursivecognitive resource we have to (re) shape neural circuits (or frames).

Keywords: Ecological Cognition. Cognitive Semantics. Framing.
\end{abstract}

\section{Referências}

ADAM, Hajo, GALINSKY, Adam D. Enclothed cognition. Journal of Experimental Social Psychology, 48(4), 1225-1398. http://dx.doi.org/10.1016/j. jesp.2012.02.008, 2012.

BARSALOU, L. W. Perceptual symbol systems. Behavioral and Brain Sciences, 22, 577-660, 1999.

DODGE, E.; LAKOFF, G. Image schemas: from linguistic analysis to neural grounding. In: HAMPE, B. (ed.). From Perception to Meaning: image schemas in cognitive linguistics. Berlin: Mouton de Gruyter, 2005.

DUQUE, Paulo Henrique. Discurso e Cognição: uma abordagem baseada em frames. Revista da ANPOLL, v. 1, n. 39, p. 25-48, 2015 a.

DUQUE, Paulo Henrique. Por uma abordagem ecológica da linguagem. UNEB: Pontos de Interrogação, v. 5, n. 1, jan. /jul., 2015 b.

EERLAND, Anita, GUADALUPE, Tulio M., ZWAAN, Rolf A. Leaning to the left makes the Eiffel tower seem smaller: Posture-modulated estimation. Psychological Science, 22, 1511-1514, 2011.

FILLMORE, Charles. Frame semantics. In: LINGUISTIC SOCIETY OF KOREA (ed.). Linguistics in the Morning Calm. Seoul: Hanshin, p. 111-137, 1982. 
FILLMORE, Charles. Topics in Lexical Semantics. In: COLE, R. (ed.). Current Issues in Linguistic Theory. Bloomington: Indiana University Press, 1977.

FILLMORE, Charles. Frame Semantics and the Nature of Language. Annals of the New York Academy of Sciences: Conference on the Origin and Development of Language and Speech. n. 280, p. 20-32, 1976.

FONSECA, Sérgio; FARIA, Christina; OCARINO, Juliana; MANCINI, Marisa. Abordagem ecológica a percepção e ação: Fundamentação para o Comportamento Motor. Brazilian Journal of Motor Behavior, v.2, n.1, p. 1-10, 2007.

GIBSON, J. J. The Ecological Approach to Visual Perception. Hillsdale, NJ: Lawrence Erlbaum Associates, 1986 [1979].

GOFFMAN, Erving. Frame Analysis. Nova York, Harper \& Row, 1974.

JOHNSON, M. The Body in the Mind: the bodily basis of meaning, imagination, and reason. Chicago: University of Chicago Press, 1987.

LAKOFF, George. The Political Mind: Why You Can't Understand 21st-Century American Politics with an 18th-Century Brain. New York: Viking, 2008

LAKOFF, George. Don't think of an elephant: Know your values and frame the debate - The essential guide for progressives. New York: Chelsea Green, 2004.

LAKOFF, George. Women, Fire, and Dangerous Things: What categories reveal about the mind. Chicago: Univ. of Chicago Press, 1987.

LAKOFF, George. Explaining Embodied Cognition Results. Topies in Cognitive Science, 4: 773-785, 2012

LAKOFF, George. George Lakoff to Green Marketers: Use the F-word. [27 de Agosto, 2013]. United Kingdom: The Guardian. Entrevista concedida a Anna M. Clark. Disponível em: < https://www.theguardian.com/sustainable-business/ george-lakoff-green-marketing />. Acesso em: 16 de dez. 2016.

LAKOFF, George. Metaphor, Morality, and Politics, Or, Why Conservatives Have Left Liberals In The Dust. In: Social Research, Vo. 62, No. 2, pp. 177-214, 1995

LAKOFF, George; JOHNSON, Mark. Metaphors We Live By. Chicago/London: The University of Chicago Press, 1980.

LAKOFF, George. Philosophy in the Flesh: the embodied mind and its challenge to western thought. New York: Basic Books, 1999.

MILES, Lynden K., NIND, Louise K., MACRAE, Neil. Moving through time. Psychol. Sci. 21, 222-223, 2010. 
NEUBERT, Albrecht. SHREVE, Gregory M. Translation as Text. Kent: The Kent State University Press, 1992.

SHAPIRO, Lawrence. Embodied Cognition. NY: Routledge Press, 2011.

SHAW, Robert E., TURVEY, Michael T., MACE, William M. Ecological psychology: The Consequence of a Commitment to Realism. In W. Weimer \& D. Palermo (Eds.), Cognition and the Symbolic Processes II (pp. 159226). Hillsdale, NJ: Erlbaum, 1982.

TOMASELLO, M. Origins of Human Communication. MIT Press, 2008.

WILSON, Andrew; GOLONKA, Sabrina. Embodied Cognition is Not What You Think It Is. Frontiers in Psychology, 4, 58, 2013.

WILSON, Margaret. Six views of embodied cognition. Psychonomic Bulletin \& Review, 9, 625-636, 2002.

ZWAAN, R. A., STANFIELD, R. A., YAXLEY, R. H. Language Comprehenders Mentally Represent the Shape of Objects. Psychological Science, 13, 168-171, 2002. 
